\title{
Regioviz: a new visualisation tool dedicated to regional comparisons
}

\author{
Ysebaert Ronan* ${ }^{\mathrm{a}}$, Guérois Marianne ${ }^{\mathrm{b}}$ \\ ${ }^{a}$ UMS RIATE, ronan.ysebaert@cnrs.fr \\ ${ }^{b}$ UMS RIATE - UMR Géographie-cités, marianne.guerois@univ-paris-diderot.fr \\ * Corresponding author
}

\begin{abstract}
Regioviz is an interactive tool developed by UMS RIATE to easily compare the French regions to the European ones. It answers to a need expressed by the State service in charge of spatial planning and territorial observation in France. This public service wanted to have a dedicated tool, easy to use, for monitoring the effects of the 2016 French regional reform on several structural indicators in a European context. This geovisualisation tool was developed in 2017-2018 and is available at the following URL <https://riatelab.github.io/regiovizlab/>. This paper presents first the story of its creation and the strong relationship linking the end-users and the developers. Then it explains how this tool works (how to set the relative position of a region, how to assess the degree of similarity with the others) and it provides 2 user-oriented scenarios.
\end{abstract}

Keywords: visualisation, tool, comparison, regions, Europe.

\section{Introduction - General scope of Regioviz}

Regioviz is an in interactive tool which aims at easily comparing the French regions to the European ones. This tool which was developed in 2017-2018 by UMS RIATE answers to a need expressed by the Observatoire des Territoires (CGET), a public organisation under the supervision of the Prime Minister in France in charge of territorial observation at State level. This organisation has supported a request coming from French regional stakeholders (Secrétaires Généraux aux Affaires Régionales - SGAR) who needed a new user-friendly tool for monitoring the effects of the 2016 French territorial reform (fusion of regions) on the relative positioning of their region at European scale. Indeed, the French regions have already developed methods for territorial observation, that enable them to know quite well the internal organisation of their territory and thus to provide information for the territorial diagnoses required by the legislation. However, the territorial reform as well as the globalisation process imply for the French regions to position themselves in an international context. On the basis of a selection of relevant indicators from a policy point of view (data availability, structural indicators), Regioviz was designed as a user-friendly tool for nonspecialists in data analysis, combining statistics and graphical methods in order to cover a double need:

On the one hand, to position a given region as compared to the others according to pre-selected socio-economic indicators. The study area may correspond to all European regions or to a subset of coherent group of regions, sharing some characteristics (population structure, geographical location, urban settlement, etc.).
On the other hand, to highlight statistical similarities between regions.

This paper presents the conceptual framework underlying Regioviz (part 2), explains the main functions of the user interface (part 3), before providing two examples of useroriented scenarios (part 4).

\section{A rise of methods and tools dedicated to geovisualisation}

2.1 When interactive maps and graphics help to better understand territorial dynamics

Regioviz takes part of geovisualisation tools since it refers to a tool supporting the analysis of geospatial data through the use of interactive visualisation. Beyond the great diversity of existing tools, many contributions on geovisualisation emphasize that the major added-value of these techniques consists in exploring, synthetizing in an interactive way geolocalised data in the perspective of knowledge creation (Dykes, MacEachren, Kraak, 2005). Indeed, "maps and graphics in this context do more than make data visible. They are active instruments in the user's thinking process" (MacEachren, Kraak, 2001).

Based on geovisualisation concepts and on informatics development, tools dedicated to analysing and comparing territories have been developed in an extensive way these last decades, in particular for monitoring indicators in a policy perspective. In the European context, we can for instance refer to the tools designed by ESPON or Eurostat $^{1}$. In most of the cases, these tools consist in

\footnotetext{
${ }^{1}$ See for instance geovisualisation tools associated to Eurostat statistics (http://ec.europa.eu/eurostat/web/regions/statisticsillustrated), or the tools developed by ESPON, such as City Bench (http://citybench.espon.eu/citybenchwebclient/)
} 
interactively associating basic cartography to a set of plots. This association allows namely to monitor the position of a region or a city within a study area which is considered relevant from a political point of view. Other geovisualisation tools designed by geographers (Tout savoir sur la population, Animer les villes,...) have highlighted the interest to associate more advanced analytical functions to these kind of tools, in order to multiply the perception of these territories (position according to the urban hierarchy, as regards to the geographical neighbourhood, to several indicators) and associate to the analysis several scales of observation.

\subsection{Regioviz, a tool derived from a collaborative work}

One of the main objective of Regioviz was to make it useful and usable for users who are not familiar with data analysis. Researches on geovisualisation highlight the importance of making clear the relations between the conceptual framework (graphics design, the analytical and methodological framework) and the collaborative work, in order to ensure an effective and operational use of the tool.

That is the collaborative state of mind in which Regioviz has been designed. Several means have been experienced at different times during the development process in order to position users at the centre of the Regioviz conceptual framework (Figure 1). The central idea was to defined adapted and intuitive visualisation techniques for sharing geospatial information: is the visualisation adapted to the statistical information we have? Is it easy to use? What kind of interactivity between maps and graphics is it possible to build?

REGIOVIz

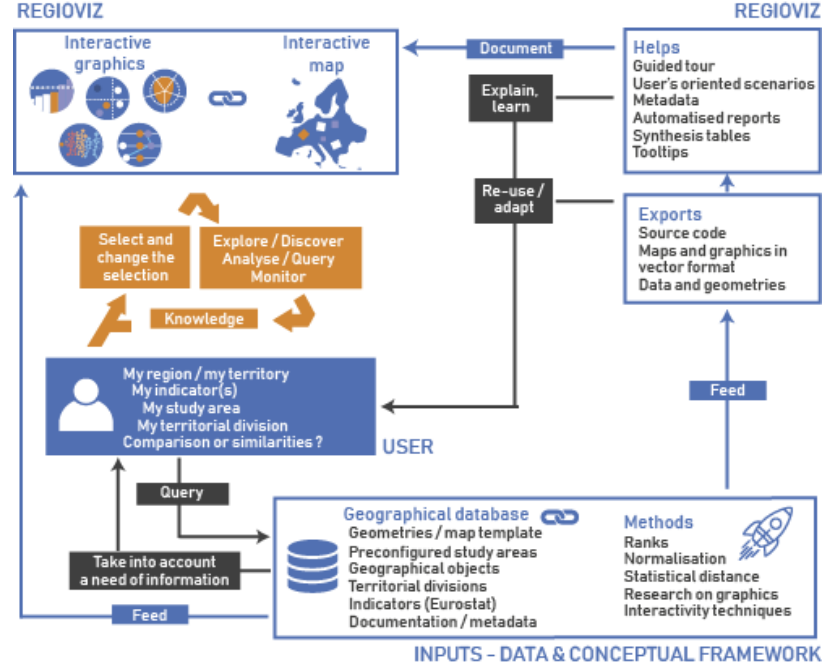

Figure 1. Regioviz framework: the user at the center of the considerations

To achieve this objective, two meetings associating the users (regional stakeholders) and the development team have been held in order to commonly discuss on the indicators selection and on the methods implemented. Based on these discussions, an important work of conceptualisation has been realised to design the tool: which geographical object and territorial divisions? Which study area? Which plot? Which statistical functions? Which data model? This conceptual work allowed to design the specifications of the tool transmitted to the Web Developer in charge of the project implementation.

For the graphical outputs, the project implementation thus refers to the literature defining the most appropriate visualisation techniques to ease the access to the information using interactivity techniques (brushing, tooltips implementation, filtering, use colours in a coherent way, contouring techniques, etc.). (Monmonier, 1989; Peterson, 1994; Jensen, 1998; Robinson, 2011; Davoine, 2016).

A survey has been realised when the first prototype of the tool was realised to collect feedbacks and to ensure that the visualisation was well understood and appreciated. These feedbacks conducted to improve and create some functionalities (for instance new visualisation techniques, possibility of creating its own study area, creation of a guided tour, etc.).

An important development of documentation materials has been realised to explain the tool to users (guided tour, user oriented scenarios, automatised reports proposing interpretation keys).

Special attention has been paid to the exports and possible re-use of Regioviz material out of the tool. To that end, all the statistical data, the geometries and the metadata used can be exported. The plots and maps designed through Regioviz can be exported in vector format (.svg).

Last but not least, the source code of Regioviz is free and open-source (CeCILL license). It is available on GitHub ${ }^{2}$. In other words, any person with database management skills can use and adapt it for other purposes (new analysis functionalities, new study areas, etc).

\section{Browse Regioviz easily}

\subsection{General organisation of the Web Interface}

Regioviz ${ }^{3}$ interface is divided into three panels. The left side is dedicated to setting the input parameters: which territorial unit ("my region")? Which territorial division? Which indicator(s)? Which study area (all regions or only those that share similar characteristics)?

The central area is dedicated to the plot where "my region" is compared to the other ones within the study area. Several modules are available depending on the number of indicators selected and on the goal of the analysis.

The right side is dedicated to the map. The selection, the plot and the map are interlinked and interactive: at any time during the data analysis the user can decide to change the selection parameters in order to provide maximum flexibility during the exploration and accompany the user in the process of knowledge creation.

\footnotetext{
${ }^{2}$ https://github.com/riatelab/rgvzall

${ }^{3}$ The tool has been designed for French users. Consequently the first prototype is only available in French. Nevertheless, the data model and the source code make the translation of the tool in other languages possible.
} 
Figure 2 shows the general organisation of Regioviz interface:

1) Region selection ("my region"). By default it proposes a random region.

2) Territorial division selection. The selection of the territorial division updates the listing of territorial units available in the menu above. It corresponds to the official division existing in Europe (NUTS1, NUTS2) where the French regions are included. A mixture of NUTS1/2 has also been implemented (first level of policy decision under the State level in Europe). It was requested by the users.

3) Indicator(s) selection.

4) Study area selection. By default, all the regions are considered (European Union). But it is possible to focus the analysis on a more restrictive study area. Firstly considering the geographical neighbourhood, by defining a buffer in kilometres around the selected region. Secondly by using a statistical filter (based on precalculated typologies) for comparing the regions sharing thematic similarities: state of belonging, level of urbanisation, demographic weight, wealth levels, economic specialization, etc. Finally and to offer the greatest flexibility for the user, it is also possible to create a study area by selecting of a set of regions directly on the map or on the plot. A scenario below (4.1) displays an example of the potential use of this functionality.

5) Analysis functions selection. These modules are further described in parts 3.2 (position) and 3.3 (similarities). Once the selection is done, the analysis can begin! Several options are implemented to ease the access to the information, displayed in green on the Figure 1.

6) In order to ensure the reproducibility of the analysis out of Regioviz, options on the top of the plot provide firstly helps for each plot (methodology, user-oriented scenario), secondly an automatized report including interpretation keys and thirdly the data, metadata and geometries displayed in Regioviz.

7) Some pre-selection tools are implemented to ease the access to information. For instance, display only territories above the study area average.

8) Options on the top of the map propose some basic actions (zooms, labels of territorial units) but also recall the degree of completeness of the indicator selection ${ }^{4}$.

9) Colours displayed between plots and maps are the same and are coherent between the modules.

10) The table below the map points out the parameters of the statistical distribution of the selection (minimum, maximum, median, average).

11) All the indicators, study areas, territorial divisions are documented by metadata, when clicking on the "i" bottom.

12) A guided tour of Regioviz is dedicated to new visitors.

\subsection{The position modules}

Three analysis modules are available for comparing the position of "my region".

\footnotetext{
${ }^{4}$ Eurostat datasets often include missing values due to territorial reforms in the different countries of the European Union.
}

The bar plot available by selecting the "position 1 ind." module allows the comparison of the selected region for one indicator, one study area and one territorial division (Figure 2). The average value of the study area is displayed with the red dashed line. With a left click on the map or the plot it is possible to identify the position of other regions as compared to the selected region (regions are displayed in red or green as compared to the selected region displayed in yellow). Moving the mouse over the bars of the plots opens an info-box setting out the name of the region, indicator values and position in the statistical distribution.

The two-dimensional graph is available when clicking on the "position 2 ind." module (Figure 3 ) for comparing the position of "my region" for 2 indicators. By default, the unit of measure of each indicator is not transformed and the red dashed line displays the average for both. But the user can choose to normalize the indicators between 0 and 100 (normalized rank), so that it is possible to say " $\mathrm{X} \%$ of the regions are characterised by lower/higher values than my region". From a visualisation point of view, regions who are characterised by values above to "my region" for both indicators are displayed in green, and red for the opposite. The regions displayed in orange and purple are in contradictory situation. The "cercles proportionnels à la population" option is useful for visualising the size of the regions in term of population as compared to the others.

The radar chart available when selecting the "Position 3 ind." module allows the comparison of "my region" for more than three indicators (Figure 4). For each indicator, values are normalized beforehand between 0 and 100 by Regioviz and the position value of the selected region are displayed on the plot by a yellow shape. The position of the median is displayed on the plot by red dashed circle (index 50). It is possible to compare the situation of the selected region to another one by a left click on the map.

\subsection{The similarity module}

Two analysis modules are available for monitoring the statistical similarities existing between "my region" and the others.

A synthetic visualisation displays the global similarities between "my region" and the others thanks to a beeswarm plot (Figure 5) associated to colours. On the left side of the plot, the regions displayed in warm colours are the closest ones to "my region" from a statistical point of view. 

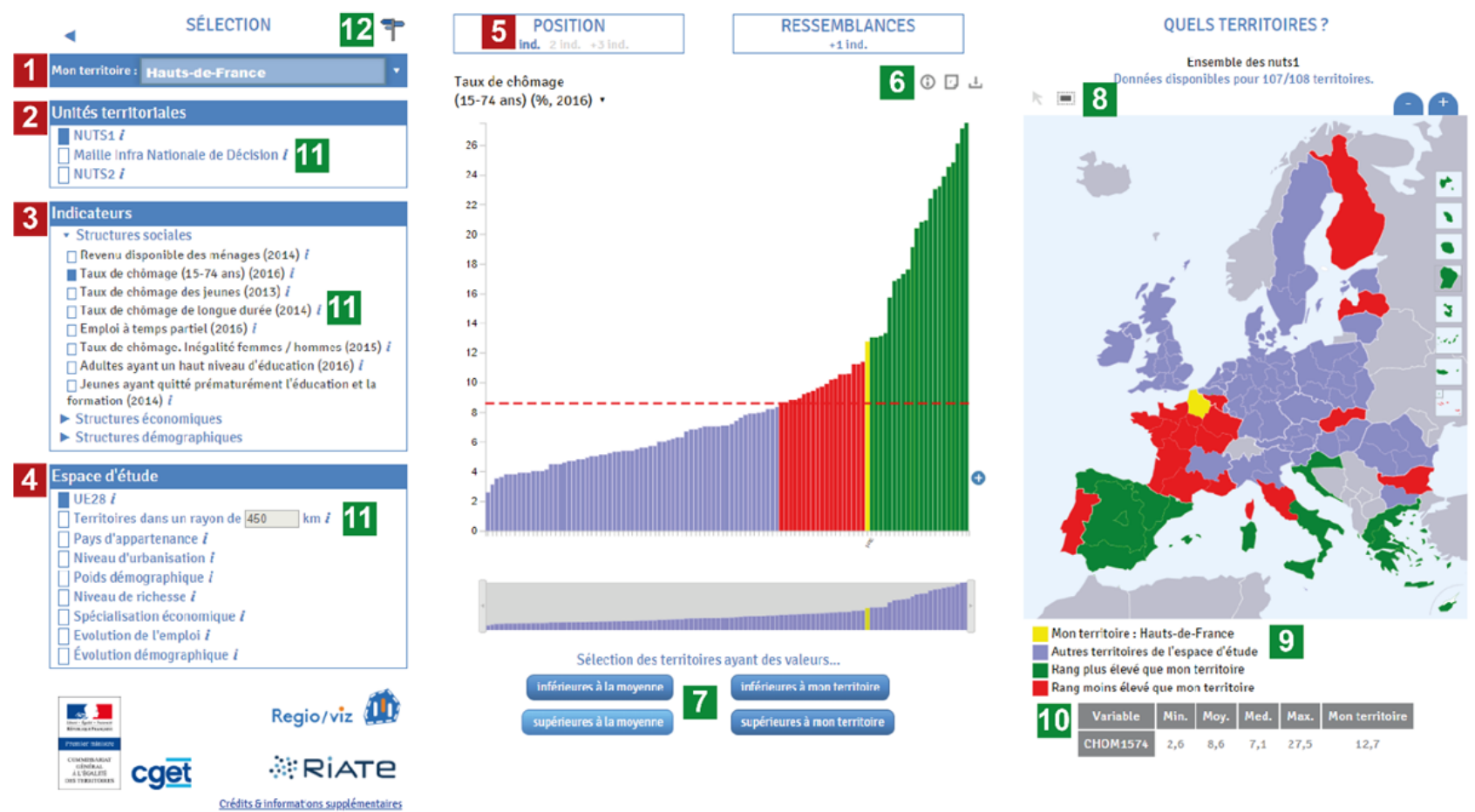

Figure 2. The Regioviz user interface. The Position 1 ind. module is displayed here

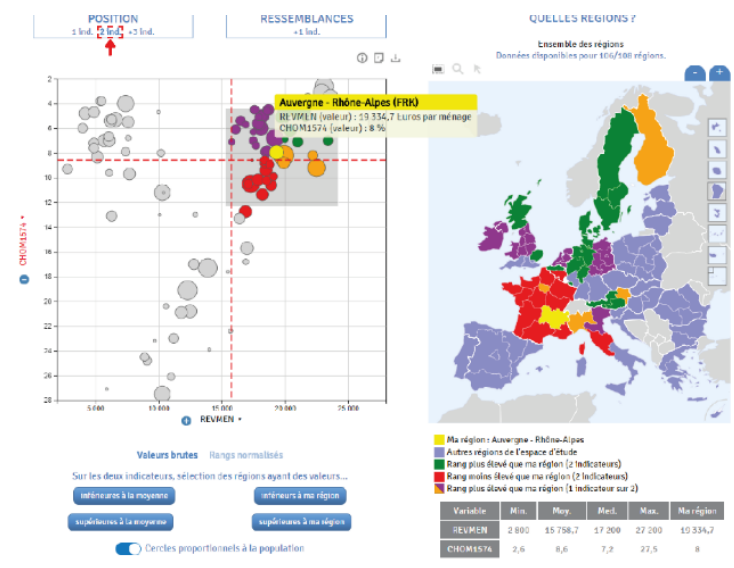

Figure 3. The "Position -2 ind." module

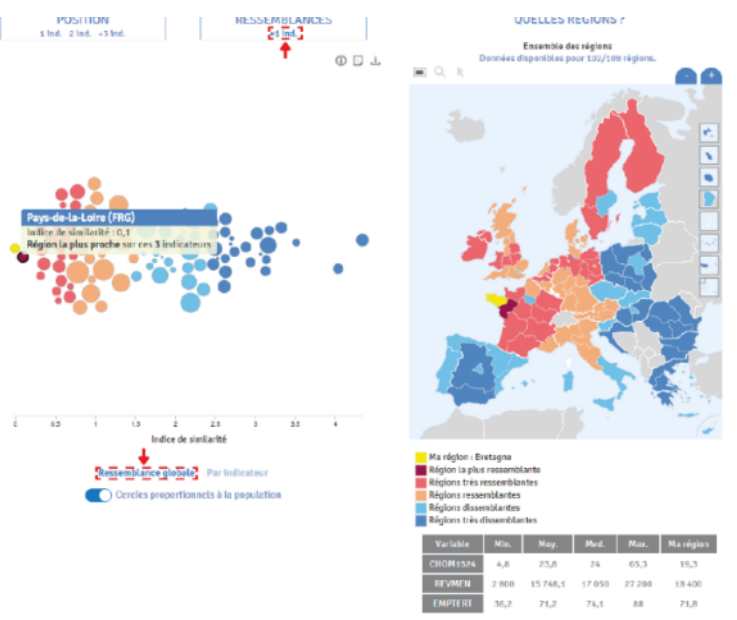

Figure 5. The "Position -2 ind." module

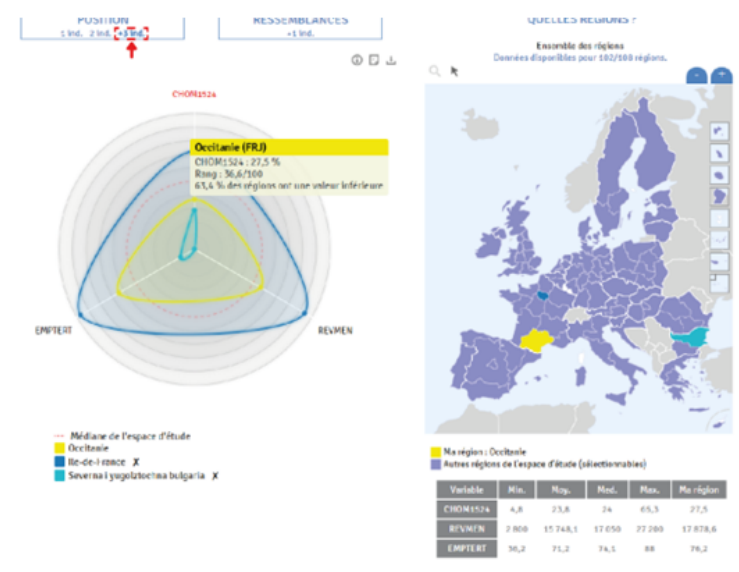

Figure 4. The "Position -3 ind." module

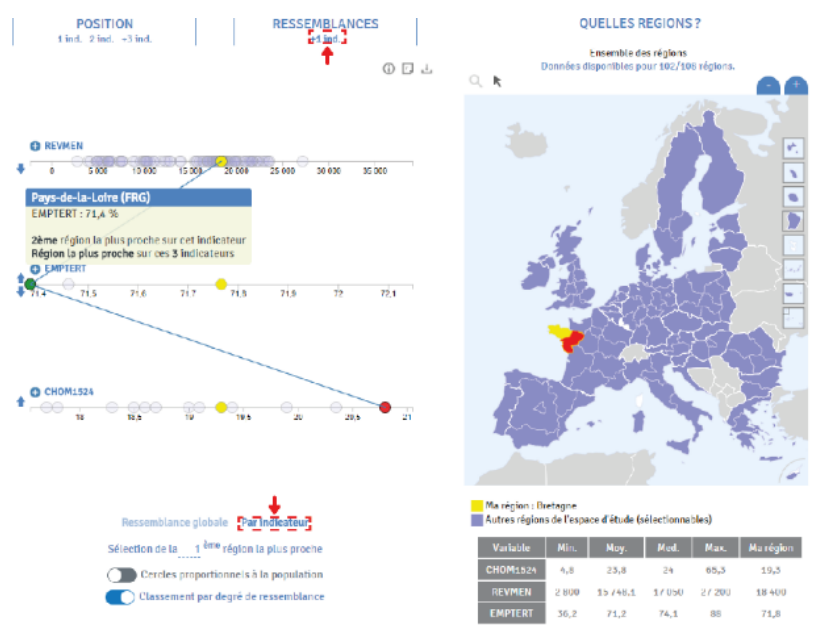

Figure 6. The "Ressemblances par indicateur" module 
The Similarities by indicator plot (Figure 6) display the distance between "my region" and the others for each indicator. It is indeed important to assess the contribution of each indicator to the global measure. By default, Regioviz displays the situation to the region which is the closest one to "my region" (positioned at the centre of the plot). But the user can choose to extend the view to the $\mathrm{X}^{\text {th }}$ closest region. It is also possible to sort the indicator by similarity degree. If this option is activated, the indicator with the closest values between two regions is displayed on the top of the combination of plots.

\section{Two user-oriented scenarios}

The scenarios displayed below provide a look into the use of Regioviz, proposing some relevant inputs regarding to the policy agenda at European level.

\subsection{The Britany position as regards to GDP per capita}

This scenario considers one of the most popular indicators used by the European Cohesion Policy: the GDP per capita in Purchasing Power Standards (PPS). This indicator is considered as a reference since 1988 for attributing the EU structural funds. For the 2014-2020 programming period, $80 \%$ of the regional policy funding (325 billion euros) is allocated to regions with a GDP per capita with less than $90 \%$ of the EU27 average and $67 \%$ for the regions with less than $75 \%$ of the average.

In this context, Regioviz can be used to introduce some new perspectives and interactive insights, by playing with the territorial division and study areas functionalities (Figure 7):

1) To begin with, we propose to select the Bretagne region, the NUTS1 territorial division, the GDP per capita in PPS in 2014 (indicator) and all the EU28 (study area, by default). With these parameters, the Bretagne region is at the centre of the statistical distribution: moving the mouse over the yellow bar, a toolbox specifies the raw value for this indicator (27 200 euros per capita) and its rank in the statistical distribution $\left(47^{\text {th }} / 108\right.$ regions). The most important value is Luxembourg (88300 euros) and the lowest one is Severna I Yugoiztochna (Bulgaria, 4600 euros). Moving over the dashed red line reminds the EU28 average: 27470 euros. Bretagne is consequently positioned a little bit above the EU28 average. But what happens when considering other study areas?

2) When limiting the study area to the regions geographically close to Bretagne (located at less than 500 $\mathrm{km}$ of the centre of the region) the situation changes considerably. The Bretagne region is now largely under the average of this new study area comprising 13 regions in France and the UK ( $8^{\text {th }}$ rank of this study area characterised by an average of 37187 euros).

3) As compared to the 18 French regions (the State of belonging), the Bretagne region is positioned at the $5^{\text {th }}$ rank. However, this region is largely under the French average (32 293 euros), due to the important weight of Paris region (Ile-de-France).
4) The selection of the regions with similar "demographic weight" than Bretagne focuses the comparison on the European regions between 2.6 and 4 million inhabitants ${ }^{5}$. This category groups mainly regions from the South-East of Europe. The Bretagne region is here in favourable situation: $9^{\text {th }}$ out of 26 regions (average: 22388 euros).

5) However, the NUTS1 level remains a statistical division including territories without specific policy relevance in term of planning. For this reason, an additional territorial division has been created, called "MIND" (the French acronym for infra national territorial division of policy decision), which combines NUTS1 and NUTS2 territorial units and corresponds to the most appropriate territorial level of policy decision for each country of the EU. When activating this territorial division and still selecting the "demographic weight" study area, the Bretagne region appears in the most populated category (regions populated from 2.7 to 17.8 million inhabitants). This category groups regions located in France, Germany, Belgium, and capitals regions. The GDP per capita average is 29972 euros, which positions the Bretagne region as the $29^{\text {th }}$ out of 58 regions.

Regioviz can thus be useful to discuss interactively on the effects of the choice of territorial division and study area to monitor socio-economic inequalities.

\subsection{Is the Grand-Est region complementary to its} neighbours in term of employment?

The aim of this scenario consists in comparing the situation of the Grand Est region (France) to its border regions: Wallonie (Belgium), Luxembourg, Sarrland and Baden-Württemberg (Germany). 7 indicators are selected for this analysis:

- 2 demographic indicators: renewal of the active population (JEUNACT) and in the next 10 coming years ${ }^{6}$ (JEUNACT10).

- 2 indicators related to the skills of the workforce: share of the active population with a high education level (EDUCSUP) and early leavers from education and training aged 18-24 years (1824NDIP).

- 3 indicators related to the labour market: unemployment rate (CHOM1574), youth unemployment rate (CHOM1524) and part-time employment (EMPART)

1) The first step consists in setting the parameters: choosing the Grand-Est region, the NUTS1 territorial division, the 7 indicators selected for the analysis and the EU28 study area (Figure 8). The "Position 3 ind." module is activated.

\footnotetext{
${ }^{5}$ In Europe, the ratio between the less populated region (Aland Islands, Finland, 30000 inhabitants) and the most populated one (Ile-de-France, France, 13 million inhabitants) is equivalent to 433 !

${ }^{6}$ The renewal of the active population corresponds to the ratio between the 0-24 years population and the 25-64 years population. The renewal of the active population in the next 10 years corresponds to the population aged $0-24$ years and the population aged 55-64 years. These two index can be interpreted as a proxy of the active population youth.
} 
1 Study area: EU28 / Territorial division: NUTS1

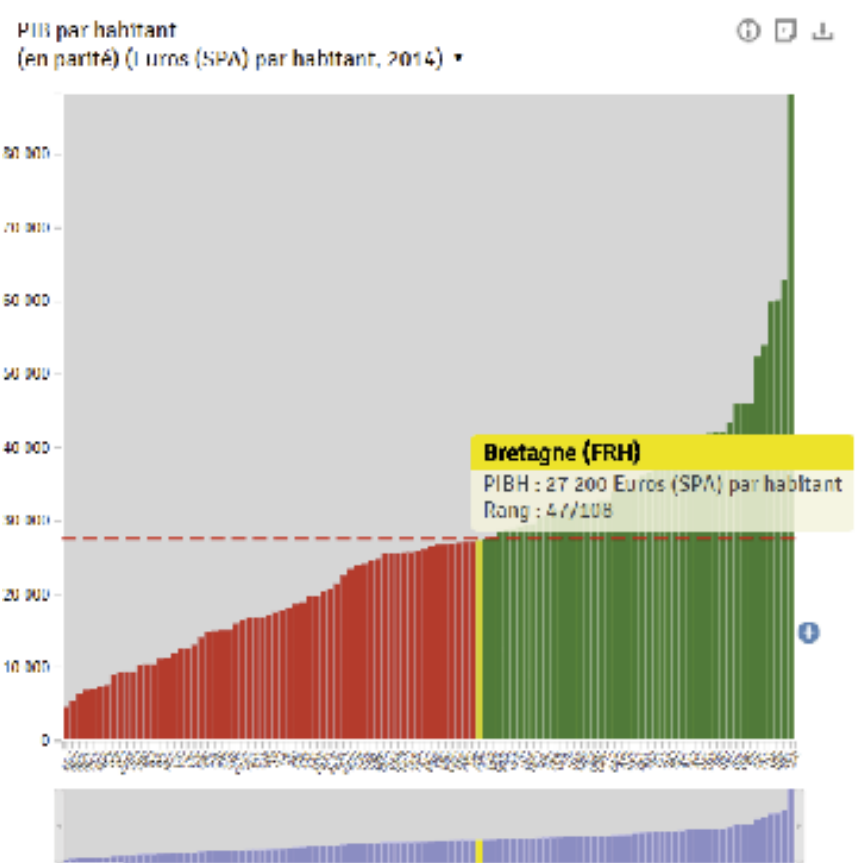

Sc̈lcetion des régions ayant des valeurs.

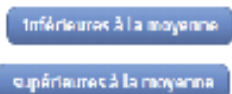

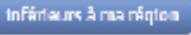

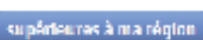

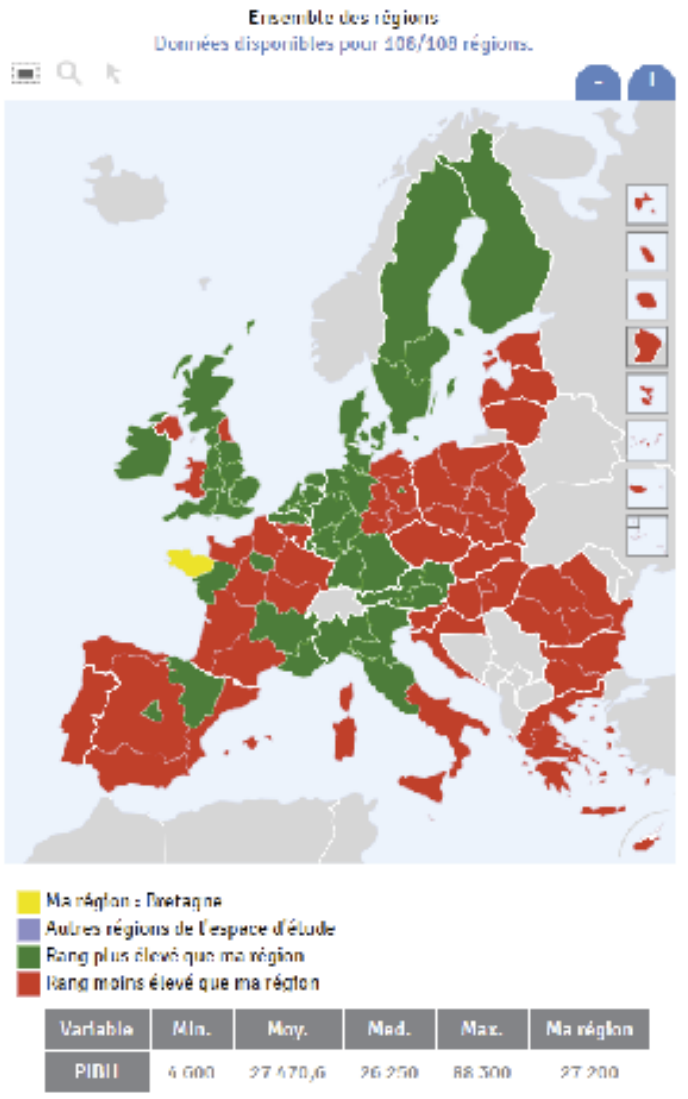

3 Study area: France

3 Territorial division: NUTS1

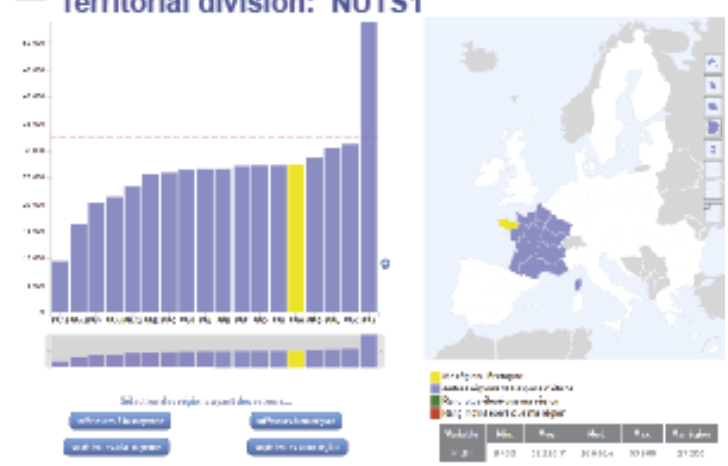

5 Study area: Similar demographic weight

Territorial division: NUTS1/2

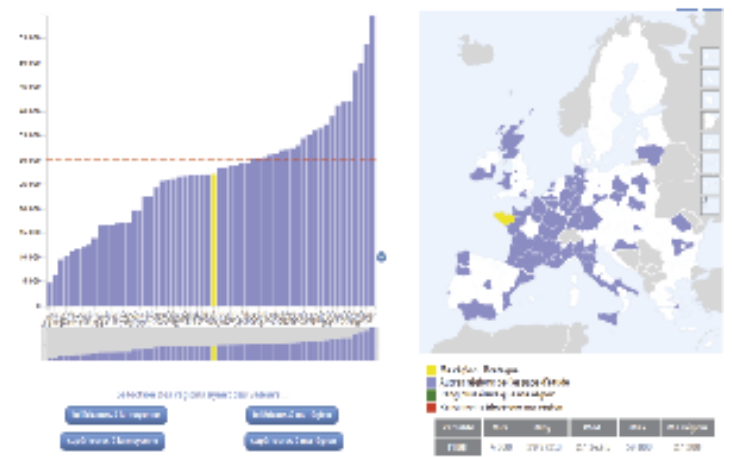

Figure 7. A scenario on Bretagne region (France) using study area and territorial division parameters 


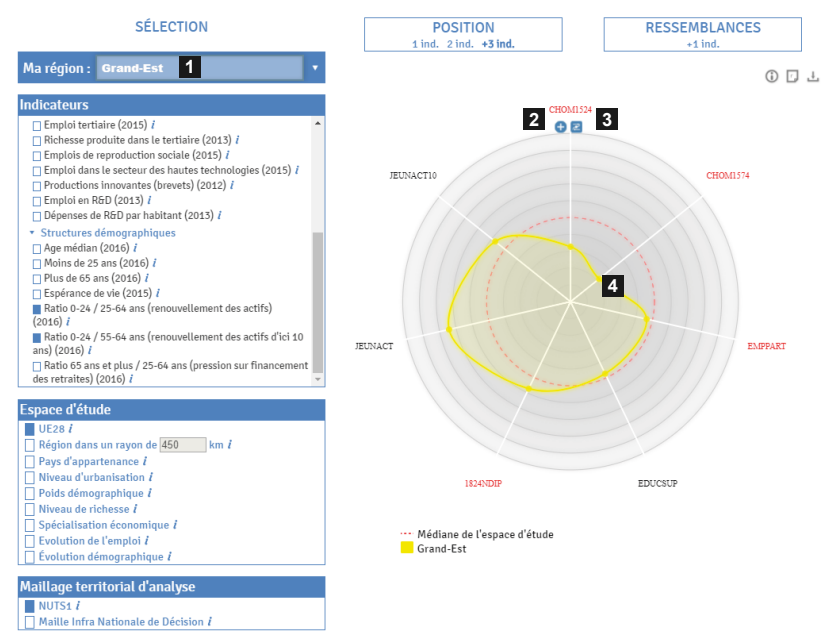

Figure 8. Position of the Grand-Est region for the 7 selected indicators

2) The indicators are reorganised by theme on the radar chart (employment on the top right, education and training on the bottom and demography on the left side).

3) The indicators are reorganised by theme on the radar chart (employment on the top right, education and training on the bottom and demography on the left side).

4) The analysis can begin! As compared to the other NUTS1 regions, the Grand-Est region is characterised by a lagging situation for unemployment indicators (index 22.7/100 for CHOM1524 and 11.4 for CHOM1574). Its position is around the European median for EMPART (index 46.5) and EDUCSUP (index 47.5). But its situation is positive for the 1824NDIP indicator $(64,3)$ and for demographic indicators (index 64.3 for JEUNACT and 57.4 for JEUNACT10). To sum up and as compared to the other European regions, Grand-Est meets some difficulties on the labour market, but it is counter-balanced by a relative positive situation in the field of education and the youth of its active population. What is the situation of its neighbouring regions? It is possible to compare the situation of "my region" to other ones by selecting them directly on the map (Figure 9).

5) The Baden-Württemberg Länder is characterised by very low unemployment rates, whatever the age-class considered. The education level of the active population is quite similar to the Grand-Est region. In that context, the low index of renewal of its active population (JEUNACT, 39.6 against 64.3 for Grand-Est) may augur complementarities on the labour market for these two cross-border regions. This findings must nevertheless be nuanced by the importance of precarious jobs in this German region: $91.1 \%$ of the European regions have a share of part-time employment lower than BadenWürttemberg (index 8.9 for EMPART).

6) Sarrland Länder is specific from the other considering its workforce ageing (index 6.9 for the two demographic indicators). The complementarity is more or less the same than with the previous region (index 85.1 for the 15-24 years unemployment rate and 78.2 for the overall workforce). But as for the rest of the German regions, the level of part-time employment is high (index 14.9).

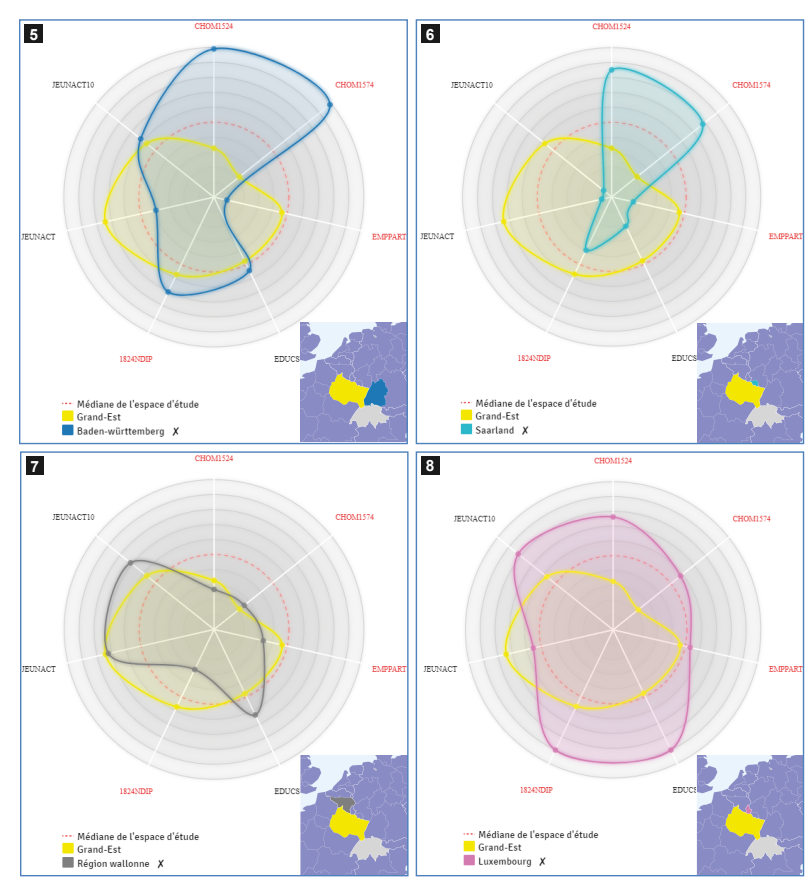

Figure 9. Comparing Grand-Est region with its international neighbouring regions

7) This complementarity differs clearly when analysing the situation of Wallonie (Belgium). This region shares more or less the same characteristics than the Grand-Est region. The only difference is observed with the early leavers from school and education (index 57.4 for GrandEst, 29.7 for Wallonie). This analysis highlights that some common challenges regarding employment and training development might interest both regions.

8) Without surprise, Luxembourg is characterised by an excellent situation for most of the indicators selected: low unemployment rates, skills of the active population, etc. The only indicator for which the Grand-Est presents a better situation is renewal of its active population (index 74.7 for Grand-Est and 55.4 for Luxembourg). But the situation is reversing when considering this renewal in the next 10 years (82.2 for Luxembourg and 57.4 for Grand-Est). This analysis points out the training challenge to access to the Luxembourg market for people living in Grand-Est region. It highlights also the relative complementarity of these two regions in a demographic point of view, which could recede in the future.

In this scenario, the use of Regioviz highlights the situation of complementarity, domination or dependence over cross-border areas. This analytical framework can support territorial observation and good practices exchanges in the framework of cooperation programs like INTERREG North-West, which is a European program funded by the European Commission with the ambition do make the North-West Europe area a key economic player.

\section{Conclusion and perspectives}

Regioviz has been delivered to the CGET in March 2018. For the CGET and the Observatoire des Territoires, Regioviz was the opportunity to test the integration of new interactive tools into their already existing 
interactive cartographic tool. Regioviz is considered as an interesting input in this context: it is the result of a demand expressed by users (regional stakeholders) who were associated with the development team during the key phases of the project implementation, from the input parameters (selection of indicators and study areas) to the testing phase of the tool (January 2018). Moreover, the investigation field of the tool is clearly identified, e.g. comparing "my region" to the European ones, staging statistical data in a way where the user is accompanied in her/his analysis. This may ease its dissemination and acceptation by final users.

The first version of Regioviz has been developed for French regions in the European context. But since the end of the project, UMS RIATE has proceeded to the adaptation of the tool to other study areas. The genericity and the robustness of the data model use and the visualisation techniques proposed by Regioviz has thus been validated. The test was successful considering that two new versions of Regioviz have been implemented, one for France (socio-economic indicators for 5 territorial division existing in France) and another one for Tunisia (results of the presidential elections of 2014 in Tunisian delegations).

\section{Acknowledgements}

To Matthieu Viry, who was in charge of the Regioviz development and who has considerably improved the initial specifications of the tool due to his researches in the domain of geovisualisation and interactivity techniques.

\section{References}

Antunez, K., Baccaïni, B., Guérois, M. and Ysebaert, R. (2018). Disparities and territorial discontinuities in France with its new regions: A multiscalar and multidimensional interpretation. Economie et Statistique / Economics and Statistics, 497-498, 19-41, Paris, France.

Arnaud, A. and Davoine, P-A. (2009). Approche cartographique et géovisualisation pour la représentation de l'incertitude. SAGEO, Paris, France.

Brennetot, A. and de Ruffray, S. (2015). Une nouvelle carte des régions françaises, Géoconfluences.

Brière, L. and Koumarianos, H. (2015). Nouvelles régions: moins de différences régionales, in La France et ses territoires, Insee, édition avril 2015, Paris, France.

Davoine, P.A. (2016). Géovisualisations. École Thématique du GDR MAGIS, Saint-Paul en Jarez, 30 May - 3 June 2016.

Dodge, M. and McDerby, M. (2008). The power of geographic visualisations, in Dodge, McDerby, Turner (eds), Geographic Visualization, Concepts, Tools and Applications, John Wiley \& Sons, Ltd, Chichester, England.

Dykes, J., MacEachren, A.M. and Kraak, M.J. (2005). Introduction Exploring Geovisualization in Dykes, MacEachren et Kraak (eds), Exploring Geovisualisation, Elsevier, pp. 1-19.
Grandjean, M. (2015). Introduction à la visualisation de données : l'analyse de réseau en histoire. Geschichte und Informatik, Chronos, 2015, pp.109-128.

Jern, M. (2009). Collaborative Web-Enabled GeoAnalytics Applied to OECD Regional Data, Cooperative Design, Visualization, and Engineering: 6th International Conference, Luxembourg, September 20-23, 2009, Proceedings, vol. 5738, p. 32-43.

Jensen, J.F. (1998). Interactivity: Tracing a New Concept in Media and Communication Studies. Nordicom Review, vol.19(1), p.185-2014.

Jouen, M. (2015). Les nouvelles régions françaises, vues d'Europe, Policy paper $\mathrm{n}^{\circ} 150$.

Kaelble, H. (2010). Les mutations du comparatisme international, Les cahiers Irice, ${ }^{\circ} 5$, pp. 9-19.

Keiner, M., Kim, A. (2007). Transnational City Networks for Sustainability, European Planning Studies Volume 15, 2007 - Issue 10, pp. 1369-1395

Keim, D., Andrienko, G., Fekete, J.-D., Görg, C., Kohlhammer, J. and Melançon, G. (2008). Visual analytics : Definition, process, and challenges in Kerren A., Stasko, J.T., Fekete, JD., North, C. (ed.) Information visualization, Berlin/Heidelberg: Springer, coll. Lecture Notes in Computer Science, vol. 4 950, p. 154-175.

Monmonier, M. (1989). Geographic Brushing: Enhancing Exploratory Analysis of the Scatterplot Matrix. Geographical analysis Volume 21(1), p.81-84.

Openshaw, S. (1981). Le Problème de l'agrégation spatiale en géographie, L'Espace géographique, 10/1, pp. 15-24.

Pasquier, R. (2012). Comparer les espaces régionaux : stratégie de recherche et mise à distance du nationalisme méthodologique, Revue internationale de politique comparée, 2012/2 (Vol. 19), p. 57-78.

Peterson, M-P. (1994). Spatial Visualization through Cartographic Animation: Theory and Practice, in Spatial Visualization through Cartographic Animation: Theory and Practice. Proceedings of Geographic Information Systems / Land Information Systems GIS/LIS, 1994, pp. 619-628.

Robinson, A.C. (2011). Highlighting in geovisualization. Cartography and Geographic Information Science, vol.38 (4), p.373-383.

Strale, M. (2012). Pour une approche critique des études de benchmarking: l'exemple de la logistique en Wallonie », in Territoire(s), http://www.territoires.be/. 